\title{
Assessing trends and predicting the cover management factor in a tropical island state using Enhanced Vegetation Index
}

\author{
Tricia Melville $^{1}$ (D) Michael Sutherland ${ }^{1} \cdot$ Mark N. Wuddivira $^{2}$
}

Received: 19 June 2020 / Accepted: 1 September 2020 / Published online: 12 September 2020

(c) Springer Nature Switzerland AG 2020

\begin{abstract}
Soil erosion is a complex process involving multiple factors that contribute to the amount of soil loss. The amount of vegetation cover is one of the main factors used to estimate soil loss and is an important risk factor in informing land use management and soil conservation policies. Cover/crop management ( $\mathrm{C}$-factor) is a dynamic soil loss factor and analysing C-factor trends in the context of both space and time, to build a multi-dimensional data structure, increased the value of the trend analysis. The objectives of the study were to (1) utilise EVI dependent static and dynamic predictive equations to compute the $\mathrm{C}$-factor, and (2) to investigate the spatio-temporal changes of the $\mathrm{C}$-factor and hotspots in a tropical small island developing state (SIDS) from 2010 to 2019. ArcGIS Model Builder was utilised to automate the computation of the C-factor using Moderate Resolution Imaging Spectroradiometer (MODIS) Enhanced Vegetation Index (EVI) data and compute the ordinary least square regression. Spatio-temporal analysis was performed using the novel emerging hot spot analysis in ArcGIS to identify statistically significant hot and cold spot trends of cover management to locate new, intensifying, persistent, or sporadic hot spot patterns at different time-step intervals. The regression output for the C-factor and EVI values indicated a strong $r^{2}$, explaining on average $90 \%$ of the models. There was no statistically significant $(P$ value $>0.05)$ increase in C-factor trend over a 10 year period $(2010-2019, P$-value $=0.92)$, a 5 year period $(2015-2019 ; P$-value $=0.59)$, or a 3 year period $(2017-2019 ; P$-Value $=0.31)$. Our results showed that intensifying hot spots (27\%) were concentrated along the north-south corridor of the study area, highlighting areas with a statistically significant increase of the C-factor, thus a reduction in vegetation cover over the study period. Integrating spatio-temporal data and spatial technology provided vital cover management estimates for soil practitioners and farmers to guide conservation strategies.
\end{abstract}

Keywords Cover management factor · GIS · Enhanced Vegetation Index · Tropical small island developing state

\section{Introduction}

Small island developing states (SIDS) in the tropics experience a combination of high-intensity storms, deforestation and poor soil management practices that cause excessive soil loss by runoff [1, 2]. Understanding the parameters over space and time that influence soil loss is necessary to inform soil conservation and management strategies.
Among the different soil erosion risk factors, the cover/ crop management factor ( $\mathrm{C}$-factor) is the one that policymakers and farmers can most readily mitigate and treat to help reduce soil loss rates [3]. However, quantitative determinations of the extent, trends and impact of soil erosion by water in tropical regions have been sketchy, and there is a conspicuous lack of credible data on the magnitude and severity of soil erosion in the tropics $[4,5]$. There are

\footnotetext{
$\triangle$ Tricia Melville, tesonia@yahoo.com | ${ }^{1}$ The Department of Geomatics Engineering and Land Management, The University of the West Indies, St. Augustine, Trinidad and Tobago. ${ }^{2}$ The Department of Food Production, The University of the West Indies, St. Augustine, Trinidad and Tobago.
} 
many difficulties associated with the monitoring, measuring and analysing trends of erosion processes. While it is true that physical models provide the optimal soil loss measurement strategy, it could be argued that direct physical measurements of soil loss are limited to small experimental plots over short time periods on which the relevant hydraulic conditions of erosion cannot be reproduced entirely [6]. Physical models are also expensive and time-consuming; therefore, a more feasible solution to measuring soil loss across the extent of a tropical SIDS are empirical models that do not compromise the efficacy of direct physical measurements. One of the most commonly used empirical soil loss models was the Universal Soil Loss Model (USLE); this model utilised predictive equations to measure soil erosion driven by water [7-9]. The USLE forms the foundation of a family of models that have proven to have the potential to estimate soil loss accurately, but require further adjustments and integration with novel geospatial technology when applied to the unique geophysical environment of tropical SIDS.

The USLE's six factors used to predict soil loss comprise of rainfall erosivity, soil erodibility, slope length, slope steepness, cover and management, and conservation practices. The cover and management factor (C-factor) is regarded as the most spatio-temporally sensitive of the USLE's six soil loss parameters, as it relies on plant growth and rainfall dynamics [10]. The cover management factor, also referred to as the crop management factor is a measure of plant cover and is defined as the ratio of soil loss from an area with specified cover and management to soil loss from the same location in continuously tilled fallow [7].

Utilising the data-intensive USLE family of models in data-poor regions of the tropical SIDS has proven challenging, as it requires extensive measured data in experimental plots. Some researchers have made necessary compromises to the computation of the $\mathrm{C}$-factor in their location-specific predictive equations $[10,11]$. The USLE/RUSLE sub-factors prior land-use, canopy cover, ground cover and within soil effects were not considered in the current study as the necessary data was not available [7]. The modifications made by researchers included using a constant $\mathrm{C}$-factor value of 1 , although the range is from 0 to 1 (Table 1). The general use of a single $C$-factor value was more prevalent in data-poor areas and may have compromised the efficacy of the results. Two soil loss studies in Trinidad and Tobago [12,13], utilised static C-factor values from existing literature to assign to land use/cover classes without making any further modification. This alternative use of land use classes to assign static C-factor values from regions without a similar geophysical environment introduces uncertainties as there was no calibration to the sensitive geophysical context of the Trinidad study area, and no consideration for time or space.

On the other hand, a study carried out on the tropical island of Jamaica [14], replaced the C-factor with a vegetation management factor (VM). The VM-factor was determined based on the product of nine forest effects and land use types on erosion, such as vegetative canopy, ground cover and roots and residues [14]. The Jamaican study inferred the VM-factor as a practical approach, but similar to the USLE model, it required extensive data and thus was not a suitable methodology for the current study.

Other tropical studies utilised regression equations to determine predictive equations for calculating the $\mathrm{C}$-factor as a form of data calibration to the specific geophysical environment [15-17]. However, the predictive equation derived from a given time-period was treated as a static model and applied to previous or subsequent years of cover management, not taking into consideration the
Table 1 Land use/cover classes and C-factor value based on literature review and identified using 2014 aerial photography

\begin{tabular}{llll}
\hline Land cover & C-factor value & EVI range for Trinidad & References \\
\hline Forest & 0.001 & 0.60 to 0.80 & {$[12,29]$} \\
Mangrove & 0 & 0.20 to 0.25 & {$[12]$} \\
Swamps & 0 & 0.15 to 0.20 & {$[12]$} \\
Mixed agriculture/broken forest & 0.15 & 0.55 to 0.65 & {$[12]$} \\
Quarries/face stone & 1.0 & 0.25 to 0.35 & {$[12]$} \\
Abandoned quarries/face stone mixed & 1.0 & 0.25 to 0.35 & {$[12]$} \\
$\quad$ with vegetation & 0.1 & & \\
Residential & 0.15 & 0.15 to 0.45 & {$[29]$} \\
Residential mixed agricultural & 0.2 & 0.45 to 0.55 & {$[12]$} \\
Cocoa trees & 0.2 & 0.50 to 0.60 & {$[12,29]$} \\
Citrus trees & 0 & 0.50 to 0.60 & {$[12,29]$} \\
Aquaculture/water bodies & 1 & 0 to -1 & {$[12,29]$} \\
Beaches & 0 to 0.25 & \\
\hline
\end{tabular}

EVI values for each land use/cover classes range from 1 to -1 
sensitive and spatio-temporal dynamics of vegetation cover. The current study attempted to address the limitations of previous studies and assessed the spatio-temporal dimension of the $\mathrm{C}$-factor. The researchers accessed the best available remotely sensed vegetation data in combination with literature from similar tropical-based research to assign to land use/cover classes (Table 1) and compute a linear regression model (Table 2). The $\mathrm{C}$-factor model has been further improved by comparing the use of dynamic and static predictive equations relative to each of the 10 years under study.

Vegetation data from remotely sensed vegetation indices provided an additional opportunity to enhance empirical predictive equations in a geographic information system environment. While many methods have been developed to estimate the cover management factor (C-factor) using the Normalised Difference Vegetation Index (NDVI) in linear regression, few have adopted a GIS workflow for both regression analysis and spatio-temporal predictions [10, 11, 18]. Even fewer studies have utilised the newer Moderate-resolution Imaging Spectroradiometer (MODIS) data product, the Enhanced Vegetation Index $(\mathrm{EVI})$, that improves upon the quality of the NDVI product (Appendix 1).

The MODIS standard Vegetation Indices (VI) products include the NDVI and the EVI. However, the current study only utilised the EVI data product. The EVI is an optimised combination of blue, red, and NIR bands [19].

$E V I=2.5\left(\rho_{N}-\rho_{R}\right) / L+\rho_{N}+C_{1 \rho R}-C_{2 \rho B}$

where $\boldsymbol{\rho}_{N, R, B}$ are reflectance in the Near Infrared (NIR), red, and blue bands, respectively; $L$ is the canopy background adjustment factor, and $C_{1}$ and $C_{2}$ are the aerosol resistance weights. The coefficients of the MODIS EVI equation are $L=1 ; C 1=6$, and $C 2=7.5$ [19].

The MODIS EVI product more effectively characterised vegetation states and processes to better encompass the

Table 2 Ordinary least square results for C-factor and EVI values

\begin{tabular}{lllll}
\hline Year & Intercept & EVI Coefficient & Adjusted $R^{2}$ & $P$ \\
\hline 2010 & 1.21 & -1.89 & 0.88 & $\mathrm{p}<0.01$ \\
2011 & 1.24 & -1.89 & 0.88 & $\mathrm{p}<0.01$ \\
2012 & 1.25 & -1.85 & 0.90 & $\mathrm{p}<0.01$ \\
2013 & 1.24 & -1.85 & 0.89 & $\mathrm{p}<0.01$ \\
2014 & 1.24 & -1.88 & 0.89 & $\mathrm{p}<0.01$ \\
2015 & 1.24 & -1.91 & 0.90 & $\mathrm{p}<0.01$ \\
2016 & 1.22 & -1.84 & 0.90 & $\mathrm{p}<0.01$ \\
2017 & 1.23 & -1.87 & 0.90 & $\mathrm{p}<0.01$ \\
2018 & 1.24 & -1.84 & 0.91 & $\mathrm{p}<0.01$ \\
2019 & 1.16 & -2.06 & 0.92 & $\mathrm{p}<0.01$ \\
\hline
\end{tabular}

range of biophysical/biochemical information extractable from vegetated surfaces. Additionally, the VI values normalised between -1 and +1 [19]. The EVI is also assumed as more suited for tropical SIDS as it does not become saturated as quickly as the NDVI when viewing rainforests and other areas of the earth with large amounts of chlorophyll [20]. The MODIS EVI has significantly improved scientists ability to measure vegetation cover and also enhanced on NDVI spatial resolution as it is more sensitive to differences in densely vegetated areas. Integrating new and enhanced vegetation indices with novel Geographic Information Systems [21] technologies such as ArcGIS Model Builder and Space Time Mining techniques, present a viable alternative to past solutions that measure and assess the spatiotemporal trends of cover management in a tropical island state using EVI.

Assessing cover management through the integration of soil loss models and vegetation indices data obtained from remote sensing platforms using GIS technology, have shown satisfactory results in more developed regions $[10,13,17]$ and has the potential for application in lesser developed states. The study area, namely the Republic of Trinidad and Tobago, is a small twin-island tropical state located in the southeastern Caribbean (Fig. 1). Trinidad lay on the South American continental shelf and was once part of South America, and the island vegetation was similar to northeastern South America [22]. The objectives of the study were to (1) utilise EVI dependent static and dynamic predictive equations to compute the $\mathrm{C}$-factor, and (2) to investigate the spatio-temporal changes of the $\mathrm{C}$-factor and hotspots in a tropical small island developing state (SIDS).

\section{Materials and methodology}

\subsection{Study area}

The study was developed in the small tropical island state of Trinidad and Tobago $\left(10.6918^{\circ} \mathrm{N}, 61.2225^{\circ} \mathrm{W}\right)$, a southeastern Caribbean country that includes two main islands, Trinidad and Tobago, and many small outer islands that together encompass $5133 \mathrm{~km}^{2}$. Trinidad and Tobago's proximity to the equator generates two opposing seasons, dry and wet. The dry season occurs during January to May, characterised by tropical maritime weather that has moderate to strong low-level winds, warm days and cool nights, with rainfall mostly in the form of showers due to daytime convection. The wet season is characterised by a modified moist equatorial weather with low wind speeds, hot, humid days and nights, a marked increase in rainfall which results mostly from migrating and latitudinal shifting tropical weather systems, during June to December 

work of the study area. a The geographical setting of the twin island state of Trinidad and Tobago within the Caribbean islands, bordered on the west by the Caribbean Sea and the east by the Atlantic Ocean. b The location of Trinidad and Tobago, highlighting the study area of Trinidad and the administrative boundaries
Fig. 1 The geographical frame-

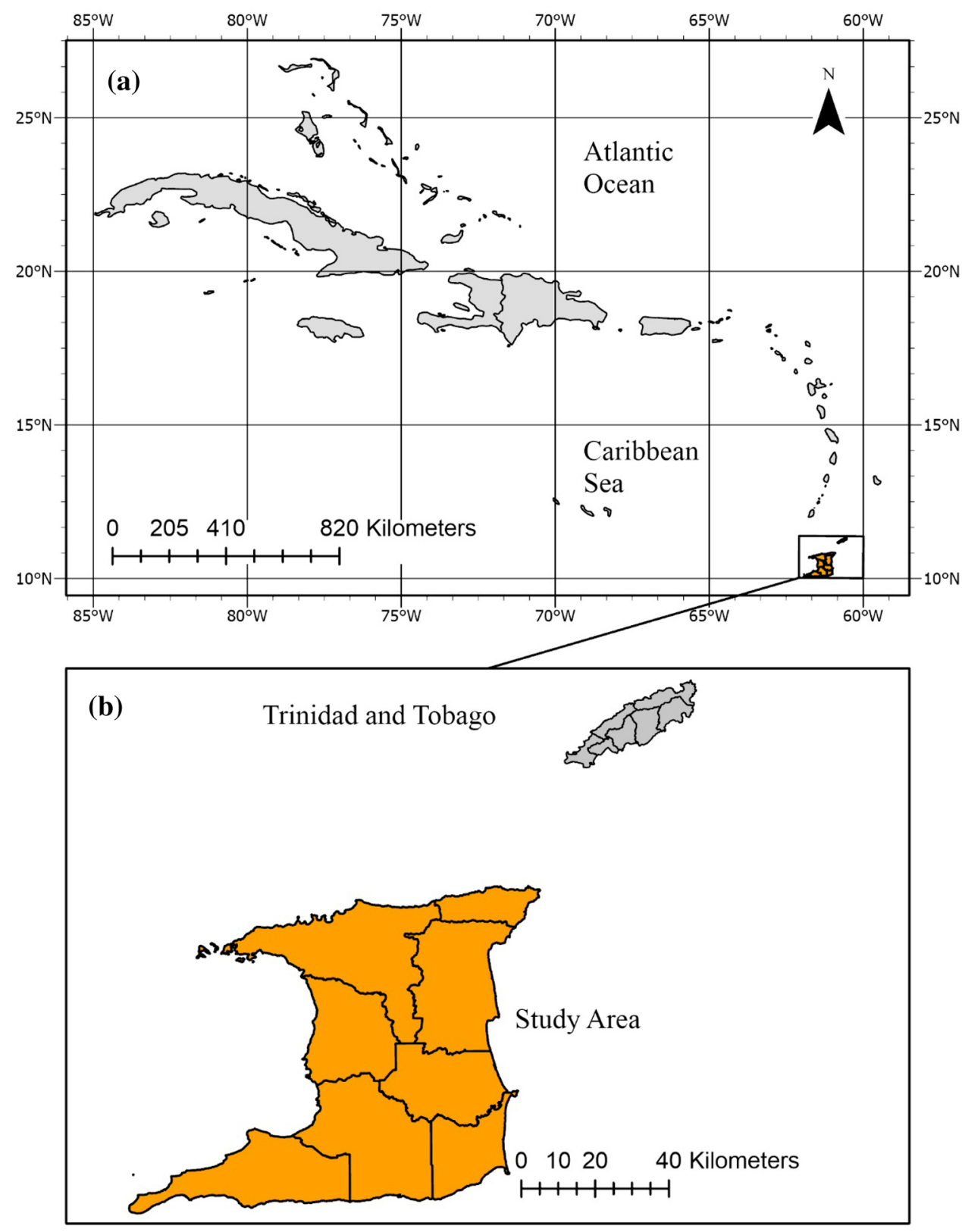

[23]. Dry season rainfall totaled $3435 \mathrm{~mm}$ and the wet season totaled 14,255 mm rainfall for 2010-2019 (Fig. 2). Most forests are moist broadleaved seasonal evergreen, but also include thick-leaved evergreen coastal, deciduous, semi-evergreen, montane evergreen, and wetland formations [24].

\subsection{Enhanced Vegetation Indices data}

In the current study, we used the EVI values derived from the Moderate Resolution Imaging Spectroradiometer (MODIS) Vegetation Indices (MOD13Q1) Version 6, and the data was generated every 16 days at 250 meters $(\mathrm{m})$ spatial resolution for the years 2010-2019 [25]. The analytical

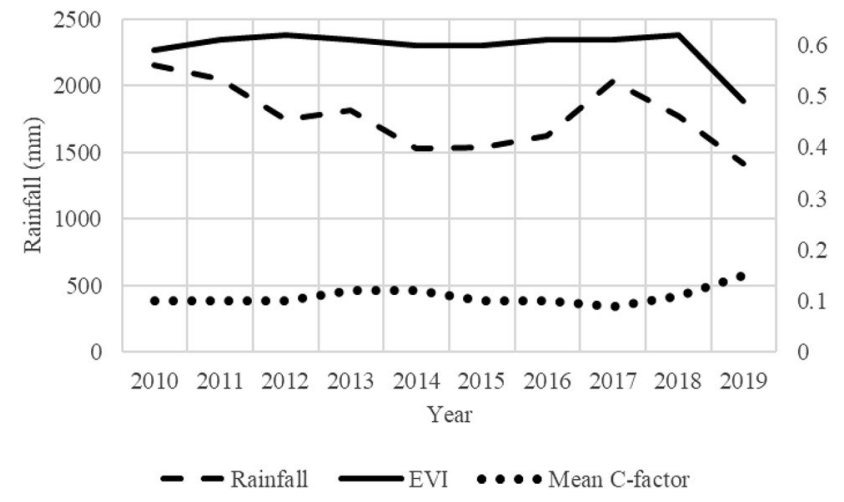

Fig. 2 Rainfall, MODIS EVI and C-factor trend lines from 2010 to $2019[22,25]$ 
procedures (Sect. 2.3) were performed in ArcGIS using the Ordinary Least Square Regression (OLS) and Emerging Hotspot Analysis tools.

The original MODIS vegetation indices values were computed by the MODIS VI algorithm in the same way, in time and space, regardless of land cover and soil type, representing true surface measurements (not modelled and no assumptions). The VI values were very accurate for most of the MODIS cloud-free pixels with a low aerosol load. However, for cases when there were no pixels of acceptable quality available within a compositing period, a lower quality observation with the maximum EVI was chosen by the MODIS algorithm to gap-fill the pixel [25]. Thus the data used in the current research was subject to inherent errors based on the quality of the pixel downloaded from the MODIS dataset.

The C-factor computation from the MODIS VI required identifying land use classes from the more advanced Enhanced Vegetation Index (EVI). The MODIS EVI products were accessed from the National Aeronautics and Space Administration (NASA) open-source platform that provided medium resolution datasets, with a spatial resolution of $250 \mathrm{~m} \times 250 \mathrm{~m}$ data from January 2010 to December 2019 [26]. The required datasets for the study area were downloaded using MODISTools. The MODISTools geoprocessing toolbox (a package for the R Statistical Computing Language) was modified from its original programming to download NDVI data to be able to generate EVI data for the study area of Trinidad from the 2010 to 2019 time period. To obtain the EVI data, the researcher reprogrammed the Import EVI script from the MODISToolbox that automated the download and post-processing procedures in ArcMap, thus reducing the risk of human error and offering an additional quality control assessment [27].

ArcGIS Model Builder was used after the complete MODIS EVI data extraction in a NetCDF format to convert the data to a more compatible format for further analysis in ArCMAP. MODISTools combined several GIS operations and ran these modules with the EVI output dataset from the MODISToolbox. Some of these ArcGIS Model Builder operations included geoprocessing tools to convert MODIS EVI data to GIS-ready format using (a) raster calculator tool; (b) the int tool to converts each cell value of the newly created raster to an integer by truncation; and (c) raster to a polygon to convert the integer type raster to a polygon feature class.

\subsection{C-factor analytical procedures performed in ArcGIS}

ArcGIS Model Builder was used to automate the computation of the $\mathrm{C}$-factor for the island of Trinidad in the current study. Within this GIS workflow, the ordinary least square (OLS) regression tool (ArcGIS) was used to estimate the C-factor values for the entire study area. Spatio-temporal analysis was performed using the Emerging Hot Spot Analysis (ArcGIS) to identify statistically significant hot and cold spot trends of cover management. The report identified new, intensifying, persistent, or sporadic hot spot patterns at different time-step intervals for the study area. Estimating C-factor values and identify spatio-temporal hotspots across the study area of Trinidad from 2010 to 2019 , formed one of the main objectives that will help to inform soil conservationist. Additionally, the study aimed to develop an ArcGIS workflow to estimate the annual cover management factor using MODIS EVI data for a tropical SIDS. The regression analysis included in this ArcGIS workflow also produced a yearly predictive equation to model the spatio-temporal cover management values for Trinidad.

The research methodology was based on geospatial statistical analysis, specifically Ordinary Least Square Regression (OLS) used to model the linear relationship between the dependent $\mathrm{C}$-factor variable and its relationship to the explanatory EVI variable. The OLS regression tool was provided in the ArcGIS Desktop, Spatial Statistics Toolbox that produced the summary of OLS results report. The output OLS regression equation was used to estimate the $\mathrm{C}$-factor values for the entire study area for further analysis. The value range of the MODIS EVI values for Trinidad was -1 to 1 . It was observed that the negative values of the MODIS EVI (values approaching -1 ) corresponded to water (coastline, ponds). Whereas, values close to zero ( -0.1 to 0.1$)$ generally corresponded to barren areas of rock or sand that were typical of mining and quarry areas. Higher, positive values of the MODIS EVI corresponded to shrub and grassland (approximately $0.2-0.4$ ), while the highest values corresponded with dense forests (values approaching 1). It should be noted that these values ranges did not exclusively correspond with the land cover specified above, given the possibility of inherent errors from the original MODIS EVI values.

After the creation of the EVI feature class detailed in Sect. 2.2, the maximum and minimum EVI values relating to the maximum and minimum vegetation cover from the visual analysis of aerial photographs (2014) were selected. The $\mathrm{C}$-factor field of the maximum value EVI features was then populated with the numerical value 0 , and the $\mathrm{C}$-factor for the minimum EVI values were populated with a numerical value of 1 . The $\mathrm{C}$-factor values range from 0 for well-protected soil/tropical rainforest to 1 for bare soil. However, the data was not available to assess the more precise value of $C$ inclusive of vegetation type, stage of growth, leaf area index and cover percentage. The 2014 aerial photography was inspected to identify general 
C-factor values ranging between 0 (very high crop cover protecting the topsoil against soil erosion) and 1 (no effect of the crop cover and high soil loss that is comparable to that of bare soil) $[8,28]$ (Table 1 ).

The EVI layer was overlaid on aerial photography (2014) for Trinidad. The study did not use aerial photography for each year under investigation as the data was not available at the necessary resolution to identify crop cover or vegetative development. A random selection from minimum $\mathrm{EVI}$ values $(<0.3)$ and maximum $(>0.6)$ was performed on the data based on land use/cover classes (Table 1). A visual check on the aerial photography was made after the random selection to ensure the values represented land use/cover classes accordingly. The maximum EVI values were selected and then verified using aerial photography within the densely forested Northern and Central Mountain Range, the corresponding $C$ value was set to 0 . The minimum EVI was identified then verified using satellite imagery scars from mining sites to represent bare soil, and the corresponding $C$ value was set to 1 . Note, negative values represented water, and after visual inspection values $<0.2$ represented the coastline and urban areas. Bare soil from mining scars and dense urban areas intersected with values $>0.2$.

The study assumes that there exists a linear correlation between EVI and the C-factor and uses bare soil and dense forest EVI values as reference values. Ordinary Least Square Regression analysis tool was run in ArcGIS on each year of the 2010-2019 EVI dataset, with known values of EVI and imputed values for the $\mathrm{C}$-factor $(0-1)$ to establish a statistical relationship. Output OLS report file detailed the results of the model variables and coefficients to develop the annual predictive equations. The line obtained after the analysis was the regression line that described the relationship between C-factor and EVI values and R showed the correlation coefficient of regression analysis. The regression equations were then used to Field Calculate the values for all of the $\mathrm{C}$-factor.

Calculated C-factor values were further analysed to predict and assess spatio-temporal trends of cover management/vegetation cover. The ArcGIS Space Time Pattern Mining toolbox was utilised to identify trends in the clustering of point densities and their corresponding C-factor values. Subsequently, the Emerging Hot Spot Analysis tool then identified statistically significant hot and cold spot trends of cover management over 1 year, from January 2010 to December 2019. Each point feature was timestamped using the input MODIS EVI data to further analyse the spatiotemporal patterns at locations throughout the study area. The result of the Create Space Time Cube By Aggregating Points tool had the option of selecting a fishnet or hexagon to create the grid cube, both had the same data points, but the hexagon was chosen for aesthetics.
The C-factor values for each bin of the cube statistics were calculated, and the trend for bin values across time at each location was measured using the Mann-Kendall statistic.

The hotspot analysis was done to analyse cover management throughout the island and located new, intensifying, persistent, or sporadic hot spot patterns at different time-step intervals. Hot and cold spot categories for the analysis and as a descriptive guide to decision-makers included: (1) new; (2) consecutive; (3) intensifying and becoming hotter over time; (4) persistent with no trend up or down; (5) diminishing and becoming less hot over time; (6) sporadic; and (7) oscillating hot and cold spots.

\section{Results and discussion}

\subsection{C-factor predictive equation}

The OLS regression provided a model of the $\mathrm{C}$-factor and was based on the EVI values.

Five statistical checks were conducted on the data; (1) probability indicated the coefficient was statistically significant, $P<0.01$; (2) the model was expected to have a negative relationship, therefore as the $\mathrm{C}$-factor increased the corresponding EVI also decreased, EVI had a negative coefficient each year (Table 2); (3) the Jarque-Bera Statistic was not statistically significant, $P>0.01$; therefore model predictions were not biased. The residuals were normally distributed and not statistically significant, $P>0.01$; (4) there was a strong Adjusted $r^{2}$ which explained $>88 \%$ of the model each year, $>0.88$ (Table 2); and (5) the model was not biased as the under and over predictions were normally distributed. The EVI was a significant predictor of $C$-factor $(P<0.0001)$ and significant regression equations were found for each year of analysis, where:

2010 C Factor $=1.21+(-1.89) *$ EVI
2011 C Factor $=1.24+(-1.89) *$ EVI
2012 C Factor $=1.25+(-1.85) *$ EVI
2013 C Factor $=1.24+(-1.85) *$ EVI
2014 C Factor $=1.24+(-1.88) *$ EVI
2015 C Factor $=1.24+(-1.91) *$ EVI
2016 C Factor $=1.22+(-1.84) *$ EVI
2017 C Factor $=1.23+(-1.87) *$ EVI

\section{SN Applied Sciences}


2018 C Factor $=1.24+(-1.84) * E V I$

2019 C Factor $=1.16+(-2.06) * E V I$

The Eqs. (2)-(11) were based on the MODIS EVI values generated every 16 days (independent variable) and considered dynamic equations used to determine the $\mathrm{C}$-factor (dependent variable). The dynamic predictive equations produced values within the standard C-factor range 1 to -1 . However, applying the single static predictive equation generated from a specific time period, such as Eq. (11) for the year 2019, to datasets from other periods produced a much lower value, not within the standard C-factor range (Fig. 3). A vital result of the current research was the difference in C-factor values when a static predictive equation was utilised on the study area versus dynamic predictive equations (Fig. 2).

The values of the dependent and independent variables should be time and space sensitive to give a more accurate mathematical model of the dynamic $\mathrm{C}$-factor. The goal of the regression analysis was to estimate the unknown values of the dependent variable (C-factor) based on the known values of the independent variable (EVI) using predictive equations. Patil and Sharma have also demonstrated the positive results of constructing a linear equation using correlation analysis between NDVI values and corresponding $\mathrm{C}$ factor values obtained from guide tables [15]. The authors established that remotely sensed data and GIS techniques offered an optimal method to estimate the $\mathrm{C}$-factor values of land cover classes of large areas.

In the current study we utilised the time and space sensitive MODIS EVI values for the study area as a dynamic independent variable. However, due to lack of available datasets on the study area, the land use/cover classes utilised in the OLS regression model were classified using

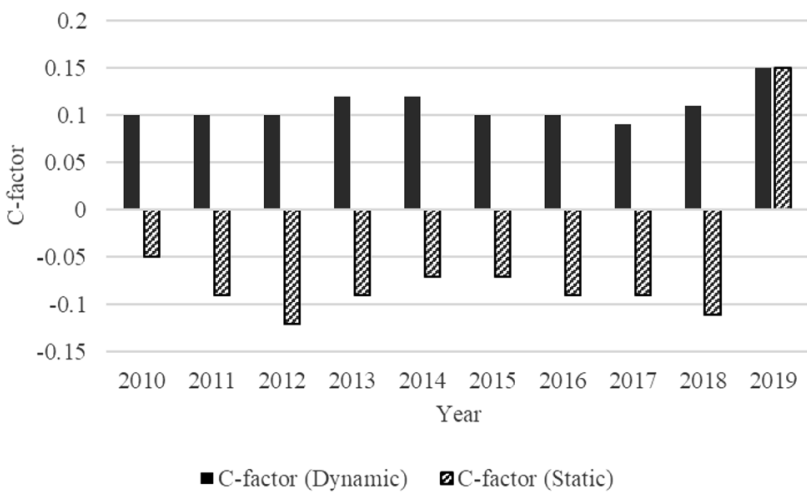

Fig. 3 Variation in C-factor values from 2010 to 2019 considering the application of $\mathbf{a}$ a dynamic predictive equations for each of the 10 years or $\mathbf{b}$ a single static predictive equation for all 10 years existing literature and identified from 2014 aerial photography. The dependent C-factor variable derived from land use/cover classes were therefore regarded as a static dependent variable. Despite this limitation, it is important to note that similar tropical studies, such as Almagro et al. [10] have shown acceptable results using a static value of the $\mathrm{C}$-factor from past literature, without considering the dynamics of the land use components. There is a lack of the literature and field experiment $\mathrm{C}$-factor data for many parts of the world, the mixed approach using freely available remotely sensed data and existing literature review have proven a viable alternative to minimise the level of uncertainty $[3,10,15]$.

\subsection{C-factor spatio-temporal trend analysis for 10 years}

The spatiotemporal analysis was conducted using the generated C-factor values from January 2010 to December 2019, 10 years of space-time trends. C-factor values were aggregated into space-time cubes of $250 \mathrm{~m} \times 250 \mathrm{~m} \times 6$ months. The space-time cube aggregated $15,140,495$ points into 167,205 hexagon grid locations over 20-time step intervals (Figs. 4 and 5). Each of the time step intervals was six months in duration, so the entire period covered by the space-time cube is 120 months $/ 10$ years. There was no statistically significant $(P$-value $>0.05)$ increase or decrease in C-factor trend over 10 year period $(2010-2019, P$-value $=0.92)$; a 5 year period (2015-2019, $P$-value $=0.59)$; or a 3 year period (2017-2019, $P$-value $=0.31)$. No statistical significance in the 10-year trend could have been attributed to the size of the islandwide study area and a large percentage of forest reserves totaling $1395 \mathrm{~km}^{2}, 27 \%$ of the islands $5133 \mathrm{~km}^{2}$. A difference in trend may have shown a statistically significant increase or decrease over a smaller study area such as a watershed or agricultural district. A study conducted in Palmares-Ribeirão do Saco watershed, Brazil from 1986 to 2007 also used remotely sensed imagery (Landsat 8) and estimated C-factor average values of 0.084 and 0.228 , respectively. The current island-wide Trinidad study and this watershed-level Brazil study both recorded high levels of vegetation cover. However, the $\mathrm{C}$-factor results obtained at the watershed-level displayed substantial greater variability in coverage indices, possibly a result of the smaller study area [17].

A summary of the C-factor values in the current study for the earliest time-series (2010), was an average value of 0.10 , and latest time-series (2019) averaged 0.27 , showing an average decline in vegetation cover (Fig. 6). However, there was a slight increase in the mean C-factor from 2013 to 2014, followed by a decrease from 2015 to 2017 and increased again from 2018 to 2019. The largest C-factor 
(a)

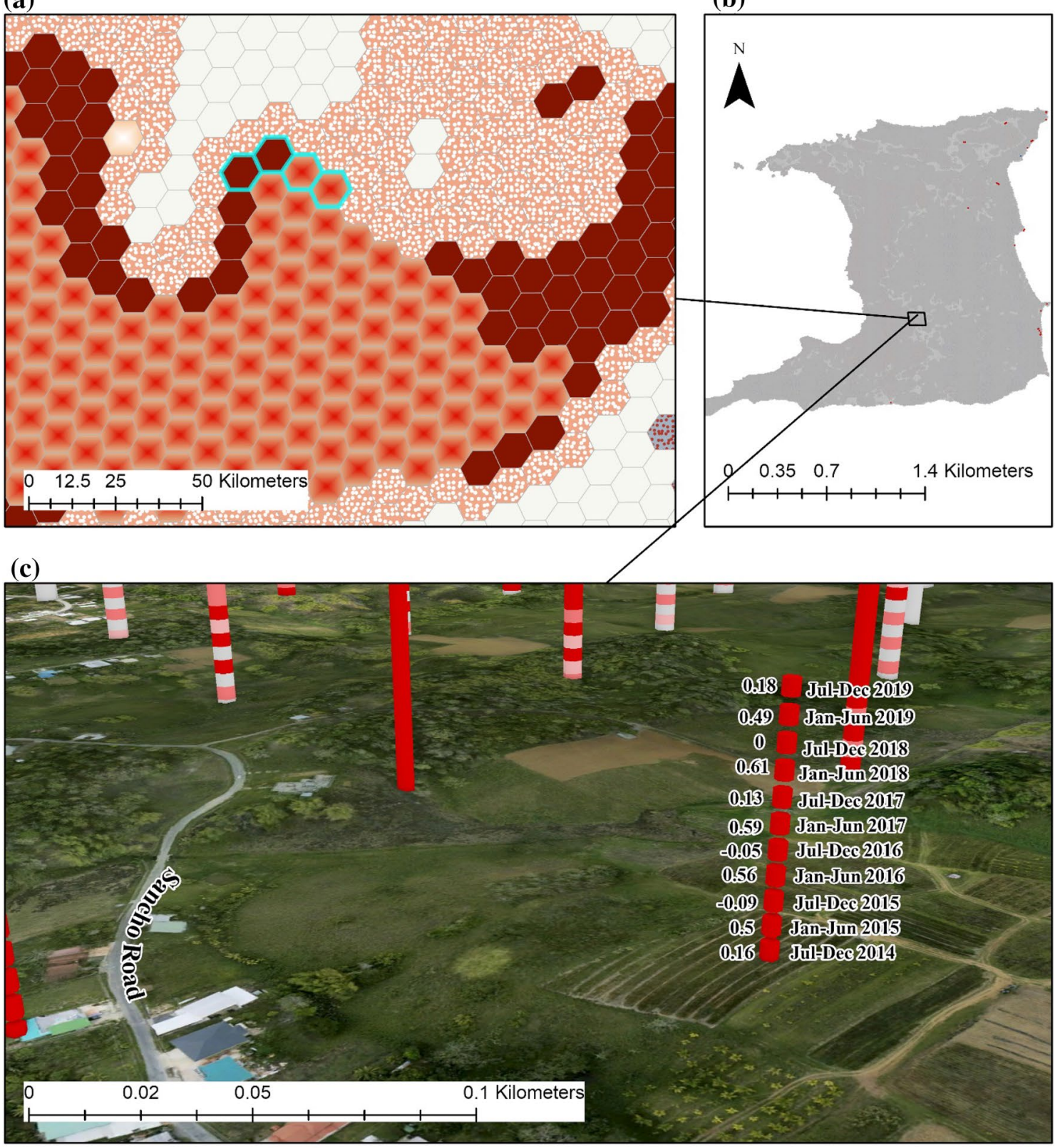

Space Time Cube
Hot Spot - 99\% Confidence
Hot Spot - $95 \%$ Confidence
Hot Spot - $90 \%$ Confidence

- Not Significant

- Cold Spot - 90\% Confidence

- Cold Spot - $95 \%$ Confidence

Cold Spot - $99 \%$ Confidence

Fig. 4 Space time cube analysis detailing a mixed agricultural and sub-urban area in Princess Town, Trinidad a 2 dimensional view of space time analysis 2010-2019 on sub-urban area; b Trinidad study area highlighting sample sub-urban location; and c 3 dimensional

increase was from 0.09 in 2017 to 0.15 in 2019, indicating a decrease in natural vegetation cover for the island. The implementation of government policy on protected areas aimed at preventing biodiversity loss in 2011 in the view of space time cube displaying the C-factor values over time on a cube over a mixed agricultural plot in the sub-urban area using aerial photography (2014)

study area [30], and may have contributed to the figures remaining constant from 2010 to 2012. This was, however, short-lived as there was a decrease in vegetation cover 2 years later from 2013 to 2014, highlighting the need for

\section{SN Applied Sciences}




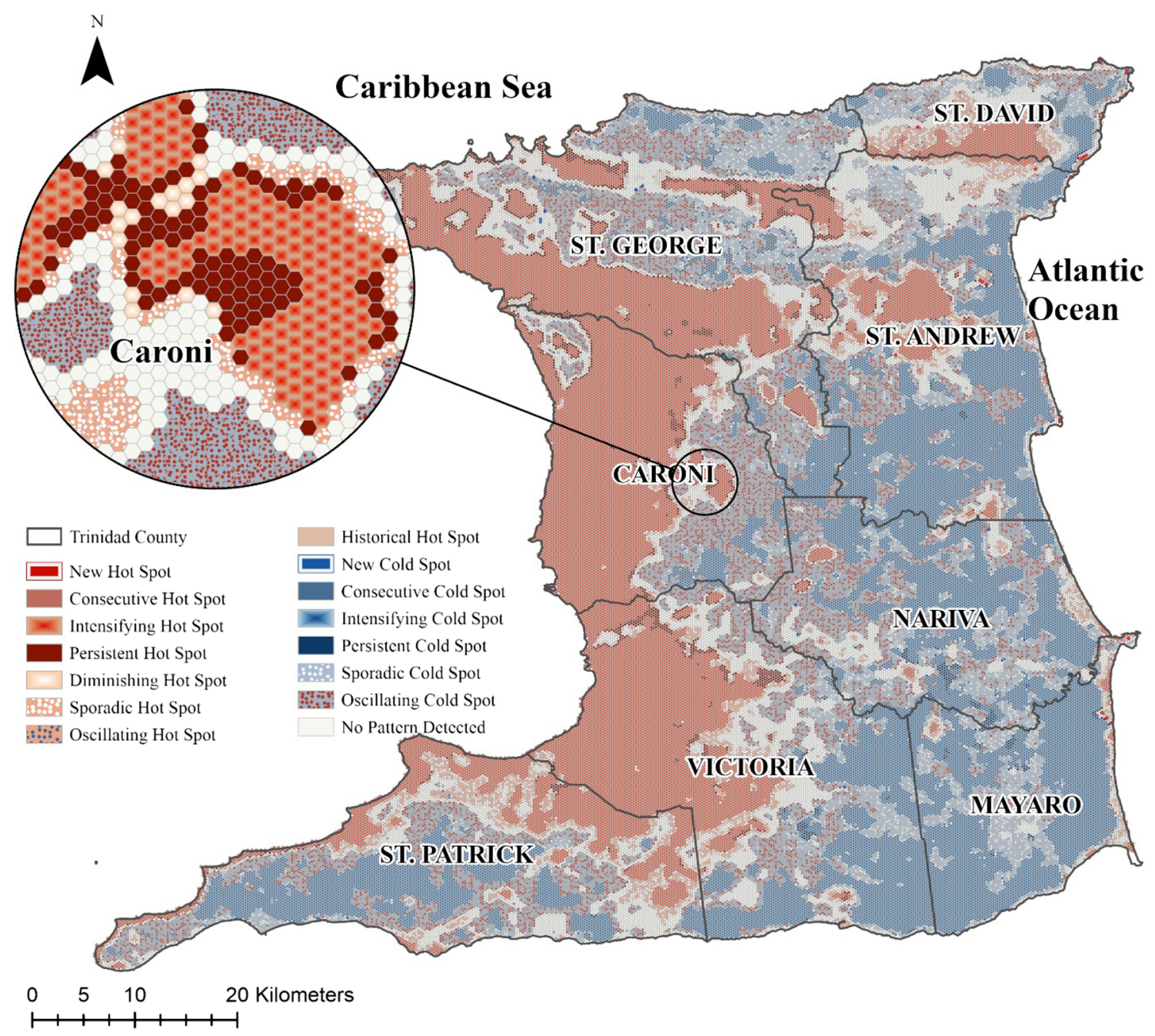

Fig. 5 Emerging Hotspot Analysis (90 months) using ArcGIS Space Time Pattern Mining

further assessment of other contributing factors such as rainfall patterns.

Seasonal fluctuations were also clearly indicated in the $\mathrm{C}$-factor value trend in each year and conformed to the two opposing seasons, with a decline in vegetation cover from the January to May dry season. It has been shown that soil moisture provides the transpirable pool of water for plants and thus, a critical controlling factor in determining the structure and density of vegetation in ecosystems [31]. Hence, during the dry season with low soil moisture, there is a decline in vegetation cover, and the reverse happens in the wet season with high soil moisture. Therefore, the $\mathrm{C}$-factor values increased in the dry season, up to 0.4 at the end of the dry season (May) in 2019, indicating scarcer vegetation cover as there was a decline in rainfall $(57 \mathrm{~mm})$ in the same month. Whereas a decrease in the C-factor values, as low as 0 at the end of the wet season in December 2019, indicating increased vegetation cover with an increase in rainfall $(165 \mathrm{~mm})$ for the same month. The 2019 C-factor values clearly showed minimum vegetation coverage for April to May $(0.35,0.34 \mathrm{C}$-factor) towards the end of the wet season and a sharp increase in vegetation cover by the second month of the wet season, July (0.02 C-factor) (Fig. 7). The average monthly temperature did not vary as much over the year, ranging from 26 to $29^{\circ} \mathrm{C}$. However, this was expected as Trinidad's daily minimum, and maximum temperature cycle is more pronounced than its seasonal cycle [23].

\subsection{Emerging hot and cold spot assessment}

The emerging hot spot analysis was run with a neighborhood distance of $500 \mathrm{~m}$ and neighborhood time step intervals of 15, spanning 90 months (maximum ArcGIS time step). The emerging hot spot analysis utilised the Getis-Ord Gi statistic. It provided a deeper understanding 


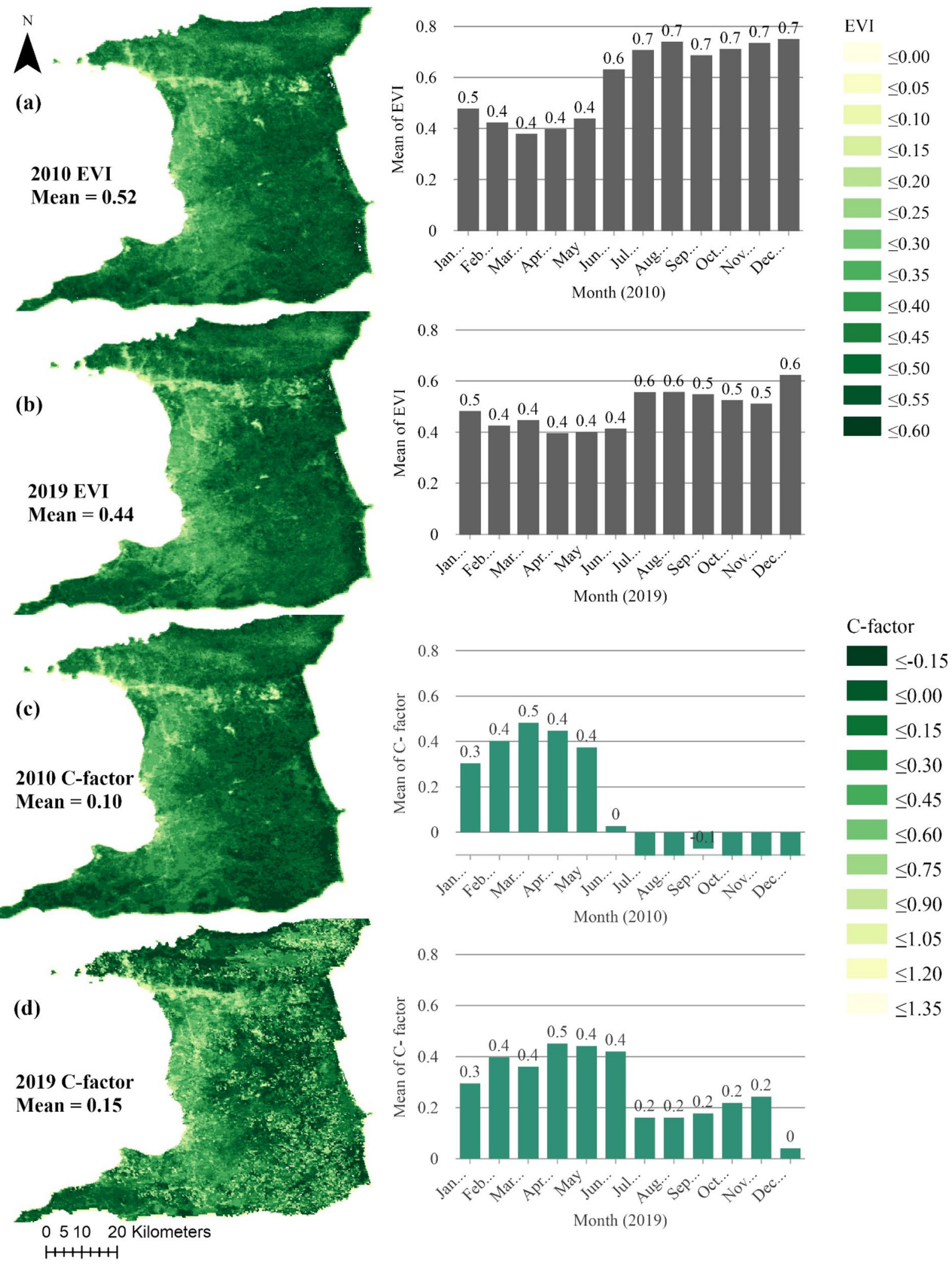

Fig. 6 EVI and C-factor results in the earliest (2010) and latest (2019) time period of the study a average monthly MODIS EVI values for 2010; b average monthly MODIS EVI values for 2019; c average monthly C-factor values for 2010; and d average monthly C-factor values for 2019 
Fig. 7 C-factor, rainfall and temperature [22] values for 2019 highlighting wet and dry seasonal fluctuations

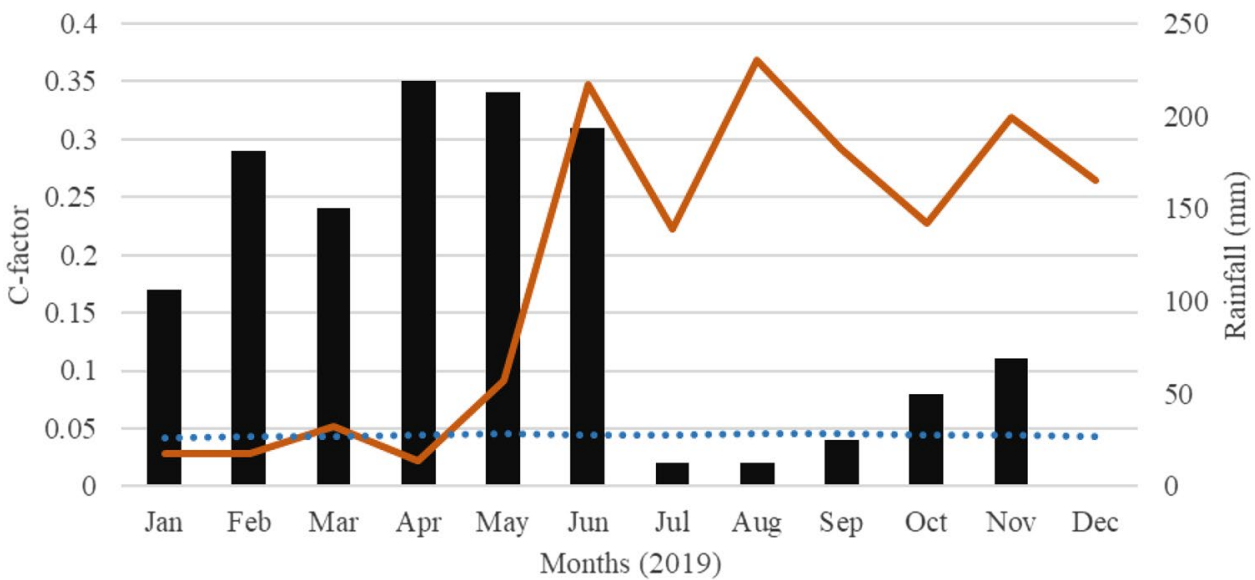

Mean C Factor $\quad$ Rainfall $\quad \cdots$ Temperature
Table 3 Hot and cold spot analysis for C-Factor

\begin{tabular}{lrrrrl}
\hline Category & \multicolumn{1}{l}{ Hot } & & \multicolumn{2}{l}{ Cold } \\
\cline { 2 - 3 } \cline { 5 - 6 } \cline { 5 - 6 } & Count & Percentage (\%) & & Count & Percentage (\%) \\
\hline New & 20 & 0.03 & 23 & 0.03 \\
Consecutive & 68 & 0.09 & 623 & 0.79 \\
Intensifying & 20,801 & 26.54 & & 21,108 & 26.93 \\
Persistent & 1792 & 2.29 & & 321 & 0.41 \\
Diminishing & 302 & 0.39 & & 0 & 0 \\
Sporadic & 5567 & 7.10 & 9579 & 12.22 \\
Oscillating & 157 & 0.20 & 18,010 & 22.98 \\
Total & 28,707 & 36.63 & 49,664 & 63.37 \\
\hline
\end{tabular}

of patterns and trends of the C-factor results, identifying hot and cold spots based on space and time (Fig. 5). Harris et al. reported that using spatial statistics such as the Emerging Hotspot Analysis tool, helped to isolate the most significant clusters of loss occurring over the dynamic forest landscapes and help focus conservation efforts [32].

In the current study, intensifying hot spots (27\%) were concentrated in the urban areas along the north-south corridor of Trinidad indicating an increase in the C-factor over the nine months; thus a reduction in vegetation cover. The $\mathrm{C}$-factor value was hot and has become hotter as these urban areas continue to expand and encroaching on neighboring vegetation. Intensifying hotspots are locations that have been statistically significant at least $90 \%$ of the time over the 90 months. New hot spots and a significant cluster of forest loss appearing in the state of Roraima in Brazil where new settlements were expanding from an existing road network have been reported [32].

Locations in central Trinidad were also of particular interest as they were categorised as persistent hotspots (2\%). These places have been consistently hot, with no significant trend going up or down (Table 3). These areas of intensifying and consistent hotspots areas of Trinidad were also focused points and areas of concern due to the trend in reduction of vegetation cover and thus increases vulnerability soil erosion. These areas require further investigation to reveal the root cause of diminishing vegetation cover. This emergence of hot spots leads to new questions about what has changed or is changing in Trinidad that has triggered a decrease in vegetation cover.

Although the C-factor hotspots should be treated as priority by soil practitioners and conservationists, the high percentage of cold spots $63 \%$ throughout the island over the past 9 months was also of interest. As is common in many other island states, Trinidad has a large area reserved for forests, almost $30 \%$ of the island which may have contributed to the higher percentage of cold spots. Similarly, $30 \%$ of the area was identified as having intensifying cold spots, meaning at least $90 \%$ of those time step intervals were cold, and becoming colder over time. On the other hand, hotspots amounted to $37 \%$ of the study area with the majority being intensifying hotspots (27\%) and a smaller percentage of persistent hotspots (2\%). These intensifying cold spots indicate areas where conservationists may learn to find mitigation techniques.

In contrast, areas of intensifying and persistent hotspots can be flagged for higher erosion risk and focus on soil conservation strategies. Further investigation was recommended to uncover the contributing factors that will also help guide decision making and mitigate areas of high erosion risk. Overall the findings prove useful to highlight areas of concern and places where past mitigation strategies may have been effective. 


\section{Conclusion}

There was no statistically significant increase in C-factor values over the 10 years (2010-2019). The C-factor fluctuated over the 10 years with a slight increase in the final year (2019). The MODIS EVI data product provided a relatively accurate dataset, although, a higher resolution would have enhanced the results even further. When the static predictive equation for 2019 was applied to each year, the results were skewed in favour of 2019. Hence, the dynamic predictive equation was calculated for each year to provide more accurate results and in keeping with the spatio-temporal analysis. The space-time analysis ArcGIS tool also offered some insight on areas that had intensifying or diminishing hotspots trends which would be of concern to soil conservationists and other soil practitioners to identify the root cause and possibly implement mitigation strategies. Cold spot areas were also an indication of decreased C-factor values and on the further investigation, can guide soil practitioners into what procedures, if any were implemented in these areas to maintain low $\mathrm{C}$-factor values.

Remotely sensed data has, therefore shown the potential for use in SIDS that are data-poor. Past research on C-factor in tropical SIDS was limited, and there were no past $\mathrm{C}$-factor variables to compare the strength of this current model for the study area. However, this study provided baseline data and methodology for the assessment of the cover/crop management values of a tropical SIDS. The C-factor was a crucial element in the overarching erosion study that further contributes to the updated and novel soil loss model for tropical SIDS, integrated with spatial technologies.

Assessing the $\mathrm{C}$-factor gives us an accurate picture of the natural vegetation cover of the island, it can also relate to the actual impact and trend of land use/cover and management factors on vegetation cover, and by extension, soil loss. This study has proven that space and time were crucial elements that should be included in $\mathrm{C}$-factor assessment and trend analysis vegetation cover is a dynamic element. It follows then that integrating spatial technologies with traditional soil loss models provided further insight into vegetation analysis.

Acknowledgements The first author would like to acknowledge The University of the West Indies, St. Augustine for providing technical support during the research. Thanks to Bryan Smith and Keron Kerwood for their encouragement and support for this research study. The authors are also thankful to the anonymous reviewers and editors for their constructive comments and suggestions, which improved the quality of the manuscript significantly.

\section{Compliance with ethical standards}

Conflict of interest On behalf of all authors, the corresponding author states that there is no conflict of interest.

Availability of data and material The datasets generated and/or analysed during the current study are available from the corresponding author on reasonable request.

Code availability Not Applicable

\section{Appendix 1}

\begin{tabular}{|c|c|c|c|c|c|}
\hline Author/Article & Imagery source & Vegetation Index & Equation & Location & Soil loss model \\
\hline$[10]$ & $\begin{array}{l}\text { Landsat } 8 \mathrm{OLI} \text { surface } \\
\text { reflectance imagery }\end{array}$ & NDVI & $\begin{array}{l}C_{r A}=0.1(-N D V I+1 / 2) \\
C_{V K}=\exp \left(-\alpha \frac{N D V I}{(\beta-n d v i)}\right)\end{array}$ & $\begin{array}{l}\text { Tropical regions- Brazil, } \\
\text { India, China }\end{array}$ & RUSLE \\
\hline$[15]$ & $\begin{array}{l}\text { IRS P6 } \\
\text { LISS III }\end{array}$ & NDVI & $C=1.02-1.21 \times N D V I$ & $\begin{array}{l}\text { Shakker river water- } \\
\text { shed, India }\end{array}$ & USLE \\
\hline$[17]$ & $\begin{array}{l}\text { Thematic Mapper (TM) } \\
\text { Landsat } 5 \text { imagery }\end{array}$ & NDVI & $\begin{array}{l}C_{V K}=e\left(-\alpha \frac{N D V I}{(\beta-N D V I)}\right) \\
C_{r}=\left(\frac{-N D V I+1}{2}\right)\end{array}$ & Brazil & RUSLE \\
\hline [33] & Landsat 8 & NDVI & $C=\exp \left(-\alpha \frac{N D V I}{(\beta-n d v i)}\right)$ & Imo State Nigeria & RUSLE \\
\hline [34] & Landsat 5 TM & NDVI & $C=1.02-1.21 \times N D V I$ & $\begin{array}{l}\text { Buyukcekmece water- } \\
\text { shed, Istanbul }\end{array}$ & USLE and RUSLE \\
\hline $\begin{array}{l}{[35]} \\
{[36]}\end{array}$ & SPOT & NDVI & $\begin{array}{l}C=((1-N D V I) \mid 2) \\
C=[((1-N D V I) \mid 2)]^{1+N D V I}\end{array}$ & Taiwan & USLE \\
\hline [37] & NOAA AVHRR imagery & NDVI & $C=\exp \left(-\alpha \frac{N D V I}{(\beta-n d v i)}\right)$ & Europe & RUSLE and USLE \\
\hline [38] & $\begin{array}{l}\text { LANDSAT Thematic Map- } \\
\text { per (TM) }\end{array}$ & NDVI & $C=\exp \left(-\alpha \frac{N D V I}{(\beta-n d v i)}\right)$ & Italy & USLE \\
\hline
\end{tabular}




\section{References}

1. El-Swaify SA, Dangler EW, Armstrong CL (1982) Soil erosion by water in the tropics. Research extension series, vol 24. University of Hawaii, Honolulu

2. Wuddivira MN, Ekwue El, Stone RJ (2010) Modelling slaking sensitivity to assess the degradation potential of humid tropic soils under intense rainfall. Land Degrad Dev 21:48-57. https://doi. org/10.1002/ldr.961

3. Panagos P, Borrelli P, Meusburger K, Alewell C, Lugato E, Montanarella $L$ (2015) Estimating the soil erosion cover-management factor at the European scale. Land Use Policy 48:38-50. https:// doi.org/10.1016/j.landusepol.2015.05.021

4. Labrière $\mathrm{N}$, Locatelli $\mathrm{B}$, Laumonier $\mathrm{Y}$, Freycon V, Bernoux M (2015) Soil erosion in the humid tropics: a systematic quantitative review. Agr Ecosyst Environ 203:127-139. https://doi. org/10.1016/j.agee.2015.01.027

5. Lal R (1999) Soil quality and soil erosion. CRC Press, Boca Rason

6. Schmidt J (2013) Soil erosion: application of physically based models. Springer, Berlin. https://doi.org/10.1007/978-3-66204295-3

7. Renard KG, Foster GR, Weesies G, McCool D, Yoder D (1997) Predicting soil erosion by water: a guide to conservation planning with the Revised Universal Soil Loss Equation (RUSLE), vol 703. US Government Printing Office, Washington, DC

8. Wischmeier WH, Smith DD (1965) Predicting rainfall-erosion losses from cropland east of the Rocky Mountains: guide for selection of practices for soil and water conservation. Agricultural Handbook, vol 282, pp 49

9. Wischmeier WH, Smith DD (1978) Predicting rainfall erosion losses: a guide to conservation planning. Agricultural Handbook, vol 537. United States Department of Agriculture, Washington $D C$

10. Almagro $A$, Thomé $T C$, Colman $C B$, Pereira RB, Marcato Junior J, Rodrigues DBB, Oliveira PTS (2019) Improving cover and management factor (C-factor) estimation using remote sensing approaches for tropical regions. Int Soil Water Conserv Res 7(4):325-334. https://doi.org/10.1016/j.iswcr.2019.08.005

11. Morgan RPC (2005) Soil erosion and conservation, 3rd edn. Wiley, Malden

12. Ramlal B, Baban SM (2008) Developing a GIS based integrated approach to flood management in Trinidad, West Indies. J Environ Manag 88(4):1131-1140. https://doi.org/10.1016/j.jenvm an.2007.06.010

13. Rawlins MA (2015) Ecosystem services approaches for natural resource planning and management in Trinidad and Tobago. The University of the West Indies, St. Augustine

14. Evelyn OB (2009) Utilising geographic information system (GIS) to determine optimum forest cover for minimising runoff in a degraded watershed in Jamaica. Int For Rev 11(3):375-393. https://doi.org/10.1505/ifor.11.3.375

15. Patil R, Sharma S (2013) Remote sensing and GIS based modeling of crop/cover management factor (C) of USLE in Shakkar River watershed. In: Paper presented at the international conference on Chemical, Agricultural and Medical Sciences, Kuala Lumpur, Malaysia, Dec 29-30, 2013

16. Carvalho DFd, Durigon VL, Antunes MAH, Almeida WSd, Oliveira PTSd (2014) Predicting soil erosion using RUSLE and NDVI time series from TM Landsat 5. Pesquisa Agropecuária Brasileira 49:215-224. https://doi.org/10.1590/S0100-204X20140003000 08

17. Durigon VL, Carvalho DF, Antunes MAH, Oliveira PTS, Fernandes MM (2014) NDVI time series for monitoring RUSLE cover management factor in a tropical watershed. Int J Remote Sens 35(2):441-453. https://doi.org/10.1080/01431161.2013.871081
18. Patil RJ (2018) Spatial techniques for soil erosion estimation: remote sensing and GIS approach. Springer, Cham. https://doi. org/10.1007/978-3-319-74286-1

19. Huete A, Didan K, van Leeuwen W, Miura T, Glenn E (2010) MODIS vegetation indices. In: Ramachandran $B$, Justice $C$, Abrams $M$ (eds) Land remote sensing and global environmental change, vol 11. Springer, New York, pp 579-602. https://doi. org/10.1007/978-1-4419-6749-7_26

20. Matsushita B, Yang W, Chen J, Onda Y, Qiu G (2007) Sensitivity of the Enhanced Vegetation Index (EVI) and Normalized Difference Vegetation Index (NDVI) to topographic effects: a case study in high-density cypress forest. Sensors (Basel) 7(11):2636-2651. https://doi.org/10.3390/s7112636

21. Pelton J, Frazier E, Pickilingis E (2015) Calculating slope length factor (LS) in the revised Universal Soil Loss Equation (RUSLE)

22. Helmer EH, Ruzycki TS, Benner J, Voggesser SM, Scobie BP, Park C, Fanning DW, Ramnarine S (2012) Detailed maps of tropical forest types are within reach: forest tree communities for Trinidad and Tobago mapped with multiseason Landsat and multiseason fine-resolution imagery. For Ecol Manag 279:147-166

23. TTMS (2018) Trinidad and Tobago Climate. Trinidad and Tobago Meteorological Service. https://www.metoffice.gov.tt/clima te_daily_data. Accessed August 42018

24. Beard JS (1946) The natural vegetation of Trinidad. Oxford University Press, Oxford

25. Didan K, Munoz AB, Solano R, Huete A (2015) MODIS vegetation index user's guide (MOD13 series). User Guide for the MODIS Vegetation Index Product, vol Version 3.00. Vegetation Index and Phenology Lab, The University of Arizona, Arizona

26. Didan K (2015) MYD13Q1 MODIS/Aqua Vegetation Indices 16-Day L3 Global 250m SIN Grid V006. https://doi.org/10.5067/ MODIS/MYD13Q1.006

27. Hydro Resource Center (2015) MODIS toolbox. Environmental Systems Research Institute, Redlands

28. Renard K, Yoder D, Lightle D, Dabney S (2011) Universal soil loss equation and revised universal soil loss equation. Handbook of erosion modelling, vol 8, pp 135-167

29. Swarnkar S, Malini A, Tripathi S, Sinha R (2018) Assessment of uncertainties in soil erosion and sediment yield estimates at ungauged basins: an application to the Garra River basin, India. Hydrol Earth Syst Sci 22:2471-2485. https://doi.org/10.5194/ hess-22-2471-2018

30. GORTT (2011) National Protected Areas Policy. Government of the Republic of Trinidad and Tobago, Trinidad and Tobago

31. Robinson D, Campbell C, Hopmans J, Hornbuckle BK, Jones SB, Knight R, Ogden F, Selker J, Wendroth O (2008) Soil moisture measurement for ecological and hydrological watershed-scale observatories: a review. Vadose Zone J 7(1):358-389

32. Harris NL, Goldman E, Gabris C, Nordling J, Minnemeyer S, Ansari S, Lippmann M, Bennett L, Raad M, Hansen M (2017) Using spatial statistics to identify emerging hot spots of forest loss. Environ Res Lett 12(2):13. https://doi.org/10.1088/1748-9326/aa5a2f

33. Okorafor OO, Akinbile CO, Adeyemo AJ (2017) Determination of Cover-Crop Management Factor (C) for Selected Sites in Imo State using Remote Sensing Technique and (GIS). Am J Environ Sci Eng 1(4):110-116. https://doi.org/10.11648/j.ajese.20170 104.12

34. Karaburun $A$ (2010) Estimation of $C$ factor for soil erosion modelling using NDVI in Buyukcekmece watershed. Ozean J Appl Sci 3(1):77-85

35. Lin C-Y, Lin W-T, Chou W-C (2002) Soil erosion prediction and sediment yield estimation: the Taiwan experience. Soil Tillage Res 68(2):143-152. https://doi.org/10.1016/S0167-1987(02)00114-9

36. Lin W-T, Lin C-Y, Chou W-C (2006) Assessment of vegetation recovery and soil erosion at landslides caused by a catastrophic 
earthquake: a case study in Central Taiwan. Ecol Eng 28(1):7989. https://doi.org/10.1016/j.ecoleng.2006.04.005

37. Van der Knijff J, Jones R, Montanarella L (2000) Soil erosion risk: assessment in Europe. European Soil Bureau, European Commission, Brussels, Europe
38. Van der Knijff JMF, Jones RJA, Montanarella L (1999) Soil erosion risk assessment in Italy. European Soil Bureau, European Commission, Brussels, Europe

Publisher's Note Springer Nature remains neutral with regard to jurisdictional claims in published maps and institutional affiliations. 